\title{
Quadruple Phase Spiral CT
}

National Cancer Institute

\section{Source}

National Cancer Institute. Quadruple Phase Spiral CT. NCI Thesaurus. Code C19908.

A type of computed tomography whereby images wihtin four separate phases following contrast medium administration are taken. 